\title{
Structural Effects in Oxide Dispersion Strengthened (ODS) Steel Neutron Irradiated to 3 dpa at $500^{\circ} \mathrm{C}$
}

\author{
Alexander Mairov ${ }^{1}$, Jianchao $\mathrm{He}^{2}$, Kumar Sridharan ${ }^{1}$ \\ 1. Department of Engineering Physics, University of Wisconsin-Madison, Madison, USA \\ 2. School of Materials Science and Engineering, University of Science and Technology Beijing, Beijing, \\ China
}

The exposure of a material to a radiation field results in the formation of point defects which, depending on temperature and dose, can then lead to the evolution of extended defects such as dislocation loops, stacking fault, voids, and bubbles [1]. These extended defects can then cause hardening and embrittlement, phase instabilities, irradiation creep, swelling. Advanced reactors are expected to operate at much higher temperatures and higher doses as compared to present LWR. Materials used for cladding and core internals should possess a combination of high creep strength and radiation damage tolerance at high temperatures [2]. Ferritic or ferritic-martensitic (FM) oxide dispersion strengthen (ODS) steels containing Y-Ti-O nanoparticles $(\sim 10 \mathrm{~nm}, 0.2$ to $0.3 \mathrm{wt} . \%$, also referred to as nanoclusters) provide this combination of properties. These nanoparticles are effective in impeding dislocation movement in the steel matrix at high temperatures, and it is hypothesized that the interfaces between the nanoparticles and the matrix act as sinks for radiation-induced defects and enhance radiation damage tolerance [3]. In this paper, we have investigated structural effects in a neutron irradiated 9\%Cr-ODS steel.

Neutron irradiations were performed at a nominal temperature of $500{ }^{\circ} \mathrm{C}$ in the Advanced Test Reactor (ATR), located at the Idaho National Laboratory (INL, Idaho Falls), up to a dose of 3 dpa. Structural examinations on nanometer length scales were performed using Transmission Electron Microscopy (TEM) and Scanning-TEM coupled with Energy Dispersive Spectroscopy (EDS). TEM samples were prepared using Focused Ion Beam (FIB) lift out techniques with a Quanta 3D FEG FEI FIB: lift-out techniques were used to reduce the volume of the samples, in order to minimize electron aberration caused by magnetic effects stemming from the ferritic/martensitic structure of these steels. TEM and STEM investigations were conducted at the Microscopy and Characterization Suit (MACS) located in Idaho Falls, using a Tecnai TF30-FEG STwin microscope operated at $300 \mathrm{KV}$.

The nominal composition of the ODS steel used in this study is shown in Table 1. The microstructure of the as received steel is complex, containing a preexisting network of dislocations, a fine dispersion of nano-scale oxide particles and coarse carbides. Radiation induced defects were analyzed with 2-beam imaging conditions, and, following the procedure outlined in Yao et al. [4], the samples were imaged close to the [100], [110] and [111] zone axis. Defects such as dislocation loops (Figure 1) and voids caused by irradiation were imaged and quantified. High-angle annular dark field (HAADF) STEM images, which provide strong Z-contrast, were employed to identify the small oxide clusters present in the matrix and quantify them before and after radiation. EDS was used to confirm the presence of Y and Ti in the oxide nanoparticles. Figure 2 shows an HAADF STEM image and EDS point scans performed on precipitates also observed in the irradiated sample [5]. 


\begin{tabular}{|l|l|l|l|l|l|l|l|l|l|l|l|l|}
\hline $\mathrm{C}$ & $\mathrm{Si}$ & $\mathrm{Mn}$ & $\mathrm{P}$ & $\mathrm{S}$ & $\mathrm{Ni}$ & $\mathrm{Cr}$ & $\mathrm{W}$ & $\mathrm{Ti}$ & $\mathrm{Y}$ & $\mathrm{O}$ & $\mathrm{N}$ & $\mathrm{Ar}$ \\
\hline 0.14 & 0.048 & 0.05 & $<0.005$ & 0.004 & 0.06 & 8.67 & 1.96 & 0.23 & 0.27 & 0.14 & 0.017 & 0.004 \\
\hline
\end{tabular}

Table 1. 9\%Cr-ODS chemical composition (wt\%, Balance Fe).

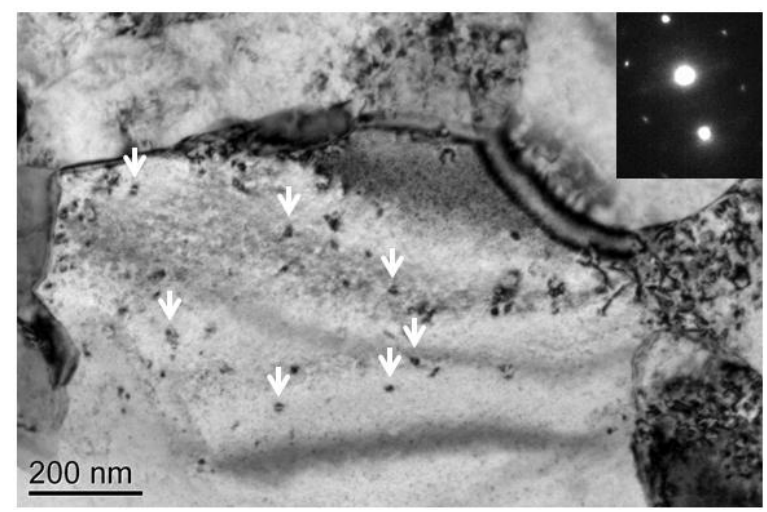

Figure 1. Bright field TEM micrograph showing dislocations loops (indicated by white arrows) in the neutron irradiated 9\%Cr-ODS steel. These loops were imaged using $\mathrm{g}_{002}$ close to the [110] zone axis. Inset shows the electron diffraction pattern close to [110] zone axis.

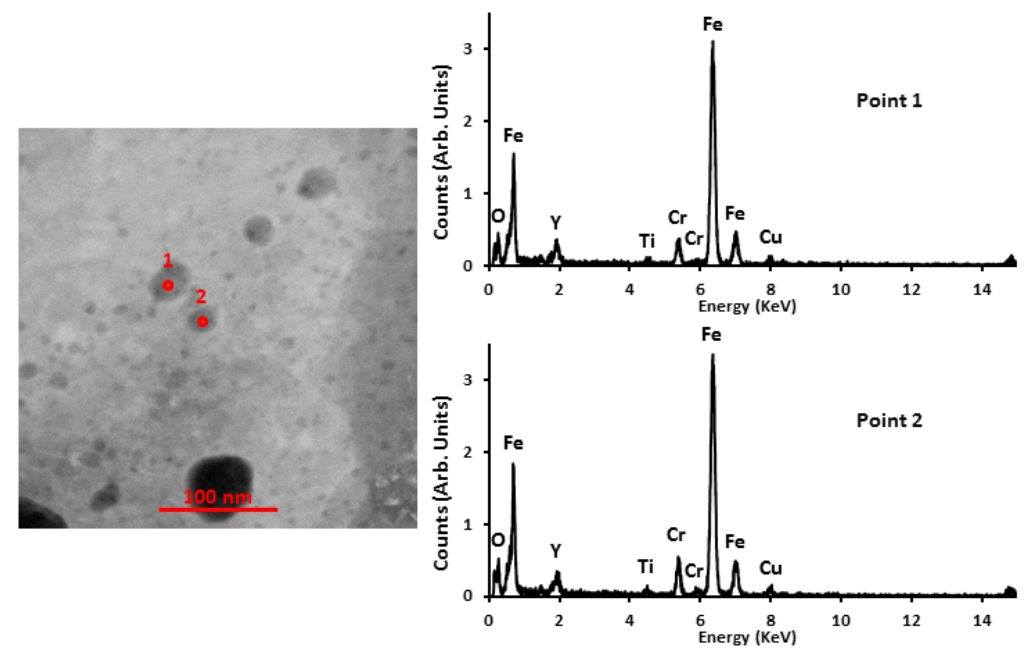

Figure 2. STEM-EDS spectra (spot analysis) collected from nanoclusters showing mainly $\mathrm{Fe}, \mathrm{Cr}, \mathrm{O}, \mathrm{Ti}$ and $\mathrm{Y}$ after neutron irradiation to $3 \mathrm{dpa}$ at $500^{\circ} \mathrm{C}$. Cu signal are from the grid on which the TEM sample is seated.

\section{References}

[1] S.J. Zinkle, Comprehensive Nuclear Materials 1 (2012), p. 65.

[2] T. Allen et al., Materials Today 13 (2010), p. 14.

[3] L. L. Hsiung et al., Phys. Rev. B. 82 (2010), p. 184103.

[4] B. Yao et al., Journal of Nuclear Materials 434 (2013), p. 402-410.

[5] A portion of this work was performed at the Center for Advanced Energy Studies (CAES) in Idaho Falls, Idaho through the Advanced Test Reactor National Scientific User Facility (ATR NSUF) award. Part of this work was performed using the NSF-supported shared facilities at the University of Wisconsin and funding from the DOE Office of Nuclear Energy's Nuclear Energy University Programs. 